\title{
Quantitative analysis of walking in patients with knee osteoarthritis: a method of assessing the effectiveness of non-steroidal anti-inflammatory
}

\section{treatment}

\author{
O Blin, J Pailhous, P Lafforgue, G Serratrice
}

\begin{abstract}
Most therapeutic tests of osteoarthritis treatments are assessed by criteria based either on fundamental data or on clinical data, which is often subjective.

A quantified analysis of locomotion can be used to determine the spatiotemporal indices (stride length and duration), kinematic indices (walking speed, velocity peak), and symmetry criteria that are relevant to the assessment of locomotor handicaps in patients with osteoarthritis.
\end{abstract}

This study examined the progression of locomotor abilities in 11 subjects aged 49-69 (mean 60.9) years with knee osteoarthritis before and after treatment with a non-steroidal anti-inflammatory drug. Naproxen sodium (1100 mg) was given once a day for seven days. The condition before and after treatment was evaluated by quantitative analysis of locomotion, estimation of pain on a visual analogue scale, and assessment of the degree of functional disability.

Significant improvement in locomotor indices (proportional increase in walking speed $17.8 \%$ ) and in degree of pain (proportional decrease $27 \%$ ) as estimated on the analogue scale was found after non-steroidal anti-inflammatory drug treatment.

The lack of a significant correlation between the decrease in pain experienced by the patients and the objective improvement of their functional capabilities emphasises the need in further studies of new treatments to accompany the patients' own assessments of self improvement with a quantitative analysis of the way in which they walk.

Clinique des
Maladies du Systeme Nerveux et de l'Appareil Locomoteur, CHU Timone 13385 Marseille Cedex 5, France O Blin

P Lafforgue

G Serratrice

Cognition et Monvement, UA CNRS 1166 , 5 rue des Géraniums, 13012 Marseille,

France

O Blin

J Pailhous

Correspondence to:

Dr 0 Blin, Clinique des Mr O Blin, Clinique des Maladies du Systeme Nerveux et de l'Appareil Locomoteur, Cedex 5, France. Cedex 5, France. 22 January 1990
The effectiveness of non-steroidal antiinflammatory drugs in the treatment of osteoarthritis is usually assessed by fundamental biological and pharmacokinetic data, ${ }^{12}$ or by a subjective clinical assessment of pain, patient satisfaction, ${ }^{34}$ or socioeconomic data. ${ }^{5}$ By analysis of locomotion it is possible to define relevant quantitative criteria for judging the locomotor handicap caused by osteoarthritis, and thus to follow up patients taking antiinflammatory drugs and assess the therapeutic effectiveness of the drug rigorously. ${ }^{6}$ Is there a correlation between the objective evaluation of locomotion made by such a method and the subjective evaluation of pain made by the subjects themselves?

\section{Patients, materials, and methods}

PATIENTS

Eleven patients (eight female, three male) aged 49-69 (mean 60.9), weight 57-100 kg (mean
$77 \cdot 5$ ), and height $150-174 \mathrm{~cm}$ (mean 162.3) were included in the study. All had knee osteoarthritis as diagnosed by clinical observation and radiography (joint space narrowing, alterations of subchondral bone-that is, sclerosis, microgeodes, and osteophytes). Duration of their osteoarthritis ranged from one to 15 years (mean 6.1 years). Five patients had osteoarthritis of the right knee, four of the left knee, and two of both knees. The osteoarthritis was painful and handicapping. All patients had difficulty in normal walking on flat ground. One patient had recurring inflammationarticular effusion, inflammatory pain at specific times. Seven patients had been successfully treated with anti-inflammatory drugs before the trial, but all antalgic or anti-inflammatory treatments had been stopped for at least three days before the study.

ETHICS

The study was approved by the Timone Hospital ethics committee, and all patients gave their informed consent to participation in the trial.

\section{EXPERIMENTAL DESIGN}

Two $550 \mathrm{mg}$ oral tablets of naproxen sodium were given once a day for seven days at the evening meal. No other antalgic or antiinflammatory treatment was allowed for 72 hours before the test or during the test. No patient took paracetamol, though this would have been permitted if necessary. Other treatments were continued without modification throughout the test.

\section{EVALUATION}

All assessments were made at the start and after seven days of treatment, under the same conditions and at the same time of day. Assessment was by a measured analysis of the patient's walk, estimation of pain on a visual analogue scale, and semiquantitative self assessment of the functional handicap while walking on flat ground and on stairs. Patients were asked about any side effects.

Quantified recording of locomotion indices The characteristics of the patient's locomotion were recorded by Bessou's locometer, ${ }^{7}$ which functions as follows. Movement of each foot pulls a string, which unwinds to the required length by means of a gearing-down pulley system. Movement is recorded as an electric signal through a pulley linked to a potentiometer. 
In this experiment the data were recorded at 75 Hz. The signal is then processed by a computer to determine timing and distances. The advantages of this apparatus have been shown previously..$^{7-9}$ This apparatus does not require any special walkway or illumination, and it can be used to record natural locomotion over a long distance (more than $10 \mathrm{~m}$ ) without any discomfort for the patients. The following indices ${ }^{10}$ may be computed by this method: (a) spatiotemporal parameters: stride length, stride duration, support phase duration, and double support phase duration; (b) kinematic parameters: velocity of the walking sequence, velocity of the swing phase, magnitude and location of the velocity peak; (c) step regularity: the standard deviation of stride length in a subject; (d) symmetry of walk: differences between step length with right and left legs, support phase duration, and velocity peak location; (e) modulation capability: an increase in velocity may result from changes in spatial factors (increase in stride length) or temporal factors (decrease in stride duration). For our patients we computed the relative contributions of spatial and temporal variables to the differences observed between normal and fast walking (voluntary modulations), and to the differences observed before and after taking naproxen sodium (involuntary modulations).

\section{Self assessment}

Patients made a self assessment of the degree of their pain on a $100 \mathrm{~mm}$ analogue scale, ${ }^{11}$ the extent of their functional disability on flat ground and on stairs, expressed by semiquantitative criteria-normal, easy, difficult, very difficult, impossible, the effectiveness of their treatment-ineffective, poor, good, very good, and how well it was tolerated-badly, moderately, well.

\section{STATISTICAL ANALYSIS}

The effects of the treatment were analysed by Wilcoxon's matched pairs signed ranks test. ${ }^{12}$

\section{Results}

TOLERANCE

Three patients had epigastralgia. Two of the three had had the same side effect previously while taking another non-steroidal antiinflammatory drug. Overall tolerance was judged to be good by seven patients, average by two, and poor by two.

\section{EFFECTIVENESS}

Overall effectiveness was judged to be high by five patients, low by five, and ineffective by one. The estimated improvement in walking on flat ground was significant $(p<0.05)$.

\section{SPATIOTEMPORAL AND KINEMATIC INDICES} OF LOCOMOTION

The table gives the mean values of the indices measured for the 11 patients. In normal walking the following differences were noted after one week's treatment: an increase in walking speed $(p<0.01)$ (fig 1) and in stride length $(p<0.02)$ (fig 2), and a decrease in stride duration $(p<0.05)$. The absolute and relative duration (with respect to the duration of the cycle) of the double support phase decreased $(p<0.01$ for both). The stance duration also decreased $(p<0.01)$. The swing velocity increased $(p<0.01)$. No significant difference was found

Spatiotemporal and kinematic locomotor indices (mean and standard deviation) of normal and fast gait in 11 patients with osteoarthritis before (upper line) and after (lower line) treatment

\begin{tabular}{|c|c|c|c|c|}
\hline \multirow[t]{2}{*}{ Indices } & \multicolumn{2}{|c|}{ Normal gait } & \multicolumn{2}{|c|}{ Fast gait } \\
\hline & Mean & $S D$ & Mean & $S D$ \\
\hline $\begin{array}{l}\text { Velocity (cm/s) } \\
\text { Stride duration (s) } \\
\text { Stride length (cm) } \\
\text { Double support duration (s) } \\
\text { Stance duration (s) } \\
\text { Swing velocity (m/s) } \\
\text { Double support duration/stride duration } \\
\text { Acceleration peak value (m/s²) } \\
\text { Acceleration peak localisation (\%) } \\
\text { Velocity peak value (m/s) } \\
\text { Velocity peak localisation (\%) } \\
\text { Symmetry step length } \\
\text { Symmetry stance duration } \\
\text { Symmetry velocity peak localisation } \\
\text { Symmetry acceleration peak localisation } \\
\text { Stride length variability }\end{array}$ & $\begin{array}{r}73.19 \\
86.19 \\
1.29 \\
1.18 \\
89.51 \\
97.82 \\
0.20 \\
0.15 \\
0.84 \\
0.74 \\
2.04 \\
2.31 \\
0.29 \\
0.25 \\
32.77 \\
50.25 \\
28.09 \\
28.52 \\
2.95 \\
3.42 \\
42.46 \\
45.23 \\
-0.13 \\
0.01 \\
-0.02 \\
-0.02 \\
-0.05 \\
-0.04 \\
-0.24 \\
-0.25 \\
2.57 \\
2.78\end{array}$ & $\begin{array}{r}21.50 \\
21.22 \\
0.22 \\
0.15 \\
18.06 \\
17.21 \\
0.09 \\
0.05 \\
0.18 \\
0.11 \\
0.51 \\
0.47 \\
0.08 \\
0.07 \\
8.10 \\
13.34 \\
10.97 \\
15.33 \\
0.71 \\
0.72 \\
9.66 \\
4.67 \\
0.39 \\
0.10 \\
0.04 \\
0.07 \\
0.36 \\
0.19 \\
0.54 \\
0.66 \\
3.94 \\
1.81\end{array}$ & $\begin{array}{r}104.84 \\
116.37 \\
1.03 \\
0.98 \\
104.21 \\
111.76 \\
0.13 \\
0.11 \\
0.64 \\
0.60 \\
2.71 \\
2.96 \\
0.24 \\
0.21 \\
46.86 \\
67.08 \\
27.83 \\
25.32 \\
3.94 \\
4.34 \\
53.50 \\
44.74 \\
0.06 \\
-0.02 \\
-0.02 \\
-0.01 \\
0.20 \\
0.04 \\
0.22 \\
0.02 \\
5.85 \\
5.24\end{array}$ & 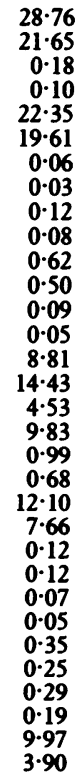 \\
\hline
\end{tabular}




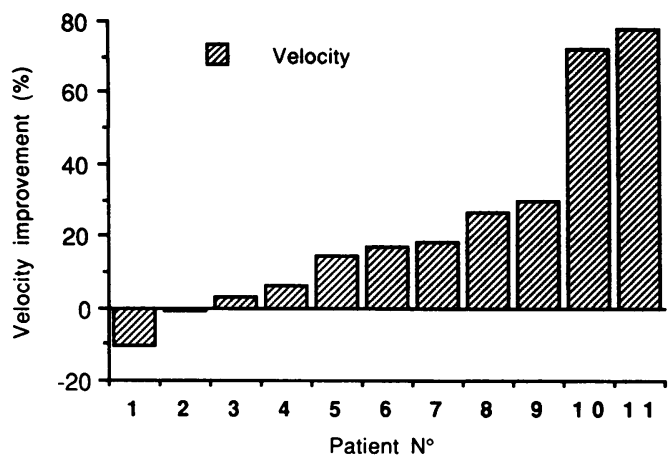

Figure 1 Velocity improvement (\%) of the 11 patients with osteoarthritis in normal gait under treatment.

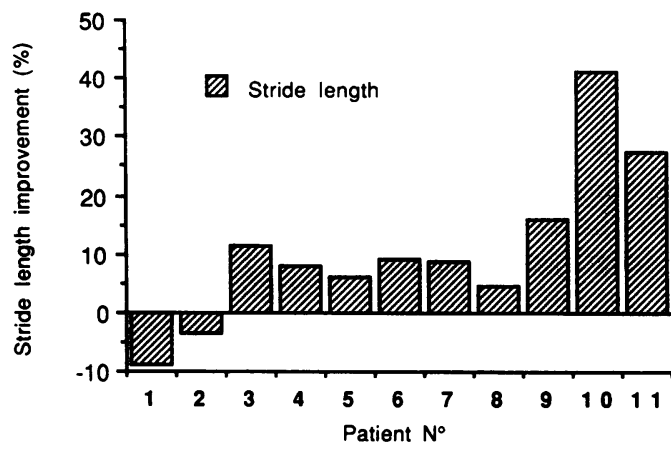

Figure 2 Stride length improvement (\%) of the 11 patients with osteoarthritis in normal gait under treatment.

in the temporal location of velocity peaks during the swing phase.

In fast walking the following differences were noted after one week's treatment: an increase in walking speed $(p<0.01)$, in stride length $(p<0.02)$, and a decrease in stride duration $(p<0.05)$. The stance duration $(p<0.05)$ and absolute double support phase duration $(p<0.05)$ decreased, but the decrease in the relative double support phase duration (with respect to total cycle duration) was not significant. No significant difference was observed in the temporal location of the velocity peaks.

\section{Regularity of walk}

Regularity of walk was analysed by studying the standard deviations of stride length in normal and fast walking. No significant difference was found.

\section{Symmetry of walk}

The symmetry criteria chosen were the differences between the right and left legs for step length, velocity peak location, and support phase duration. Data analysis showed that patients with a dissymmetrical walk (Nos 1 and 5) before treatment regained a symmetrical walk after treatment (figs 3 and 4).

\section{Velocity modulations}

We analysed the modulations in velocity made either voluntarily following specific instructions (to walk normally or to walk quickly) or involuntarily owing to treatment (fig 5). Voluntary velocity variation before treatment $(43 \cdot 2 \%)$ was $55 \%$ due to a decrease in stride

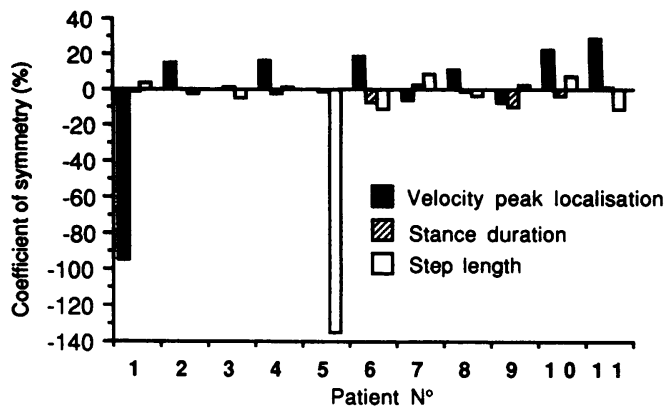

Figure 3 Coefficient of symmetry (step length $\square$, stance

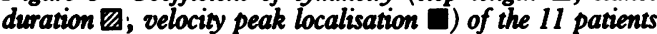
with osteoarthritis in normal gait before treatment.

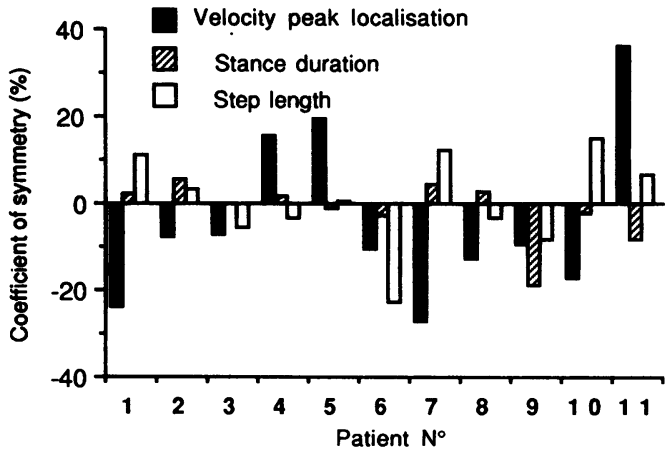

Figure 4 Coefficient of symmetry (step length $\square$, stance duration $\mathbb{Z}$, velocity peak localisation ${ }^{2}$ ) of the 11 patients with osteoarthritis in normal gait after treatment.

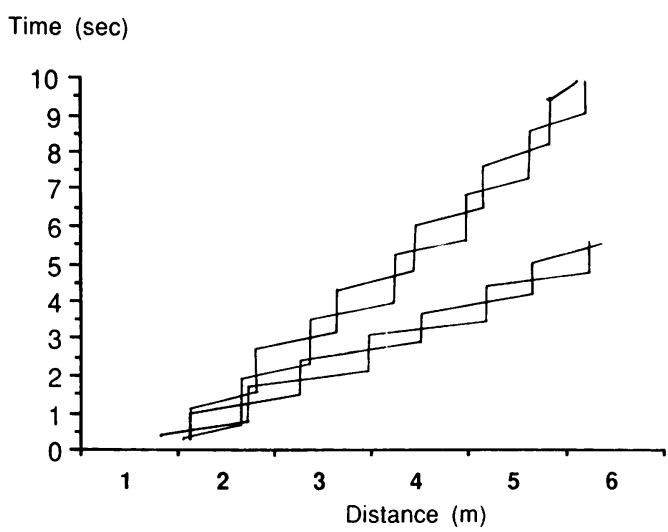

Figure 5 Relation between time (ordinate) and distance covered (abscissa) for the two feet of a patient before (upper curve) and after (lower curve) treatment.

duration and $45 \%$ to an increase in stride length. The variation in velocity due to the treatment was $17 \cdot 8 \%$ in normal walking, contributed to equally by an increase in stride length $(50.3 \%)$ and a decrease in stride duration $(49 \cdot 7 \%)$.

\section{PAIN}

A significant improvement (27\%) in degree of pain after treatment was indicated on the visual analogue scale $(p<0.01)$. No significant correlation was found after treatment between the proportional decrease in degree of pain (as assessed on the visual analogue scale) and the proportional increase in walking speed $(r=0 \cdot 17)$, the proportional increase in stride length $(r=0 \cdot 14)$, or the proportional decrease in stride duration $(r=0 \cdot 07)$. 


\section{Discussion}

Few quantitative studies have been conducted on the locomotion of patients with osteoarthritis. With knee lesions several different compensation mechanisms may be implemented, ${ }^{13}$ including a decrease in support phase duration, a decrease in the amplitude of knee movement, external rotation of the hip on the afflicted side, and a decrease in the amount of ground support accompanied by damping of foot contact (shuffling gait). The foot remains close to the ground and step length decreases on the afflicted side, leading to a decrease in forward-backward velocity. In the case of stiffening, limping owing to the unequal length of the legs may occur. Stiffening on extension is compensated for by raising the pelvis on the ankylosed side, putting the leg into hip circumduction, or by walking on the tip of the foot contralateral to the lesion. ${ }^{14}$

Our study shows, however, that in contrast with these clinical descriptions, patients with osteoarthritis of the knee do not decrease the duration of the support phase on the diseased leg, even in cases of a highly dissymmetrical walk (fig 4). The improvement found in most patients after treatment with naproxen sodium can be directly visualised by plotting the distance covered against time. The improvement is immediately apparent on these graphs, and corresponds to objective, clinically significant indices (fig 5). Note that with naproxen sodium treatment the velocity and stride length of most patients increased. The increase in the value of the velocity and acceleration peaks reflects the improved dynamic quality of their walk after treatment. Before treatment the patients modified their velocity primarily by decreasing the duration of their strides. This can easily be explained by the handicapping mechanical and pain related constraints to which they are subject. With treatment velocity increases were brought about by proportionate increases in stride length and decreases in stride duration-a strategy also used by healthy controls of the same age. It should perhaps be noted here that there is a difference between the mechanisms underlying velocity variations made voluntarily, and those underlying variations due to a treatment which reduces the mechanical constraints to which the patient is subject.

In summary, naproxen sodium treatment had an undeniably positive effect on the amount of pain experienced (mean decrease of pain 27\%) and the functional abilities of the patients studied (mean increase of walking speed $17 \cdot 8 \%$ ). These two types of improvement were not correlated, however-that is, the increased walking speed was not linked to the decrease in pain. This finding stresses the value of simultaneously analysing the effects of a new therapeutic treatment on both pain and functional abilities in order to judge its effectiveness.

This study was supported by Recherche Syntex France.

I Sevelius H, Runkel R, Segre E J, Bloomfield S S. Bioavailability of naproxen sodium and its relationship to clinical analgesia. Br 7 Clin Pharmacol 1980; 10: 259-63.

2 Bruno $R$, Iliadis A, Jullien I, et al. Naproxen kinetics in synovial fluid of patients with osteoarthritis. $\mathrm{Br} f \mathrm{Clin}$ synovial fluid of patients

3 Asch L, Dreyfus P, Kuntz D, Simon L. Etude comparée du naproxène sodique et du diclofénac dans le traitement de la naproxène sodique et du diclofenac dans le traitement de la (suppl): 28-30.

4 Kuntz D, Lagoarde J, Loyau G, Tazi A. Etude comparée de l'activité du naproxène sodique et de l'indométacine dans le traitement de la gonarthrose. Foumal International de Medecine 1985; 56 (suppl): 25-7.

5 About V, Corrion F, Lamotte J. Arthrose: approche socioéconomique chez 10257 patients. Actualités thérapeutiques. FAMA (Hors Série) 1987: 8-10.

6 Paul J P. Gait analysis. Ann Rhewn Dis 1989; 48: 179-81.

7 Bessou P, Dupui P, Montoya R, Pages B. Simultaneous recording of longitudinal displacements of both feet during recording of longitudinal displacements of bot

8 Ferrandez A M, Pailhous J, Serratrice G. Locomotion in the elderly. In: Amblard B, Berthoz A, Clarac F, eds. Posture and gait: development, adaptation and modulation. Amsterand gait: development, adaptation

9 Blin O, Ferrandez A M, Pailhous J, Serratrice G. Une nouvelle méthode d'analyse quantitative de la marche du Parkinsonien: illustration sur 6 patients. Rev Neurol (Paris) 1990; 1: 48-50.

10 Inman V T, Ralston H J, Todd F. Human walking. London Williams and Wilkins, 1981.

11 Scott P J, Huskisson E C. Graphic representation of pain. Pain 1976; 2: 175-84.

12 Siegel S. Non parametric statistics for the behavioural sciences. New York: McGraw-Hill, 1956.

13 Plas F, Viel E, Blanc Y. La marche humaine. Kinésiologie dynamique, biomécanique et pathomécanique. Paris: Masson, 1985.

14 Ducroquet R J, Ducroquet P. La marche et les boiteries. Paris: Masson, 1965. 